\section{Commentary: Saphenous vein graft patency after coronary artery bypass grafting. It's all about getting the basics right}

\author{
Shuab Omer, MD
}

Optimal efficacy of coronary artery bypass grafting (CABG) remains compromised because of vein graft attrition and progression of native coronary artery disease. A total of $10 \%$ to $20 \%$ of vein grafts fail at 1 year and almost $50 \%$ at 10 years. ${ }^{1,2}$ Despite this dismal performance, the saphenous vein graft still remains the most commonly used conduit for CABG surgery.

Vein graft patency depends on modifiable and nonmodifiable factors, including native coronary artery disease burden, quality of vein, technique of vein harvest, surgical technique, on-pump versus off-pump, use of antiplatelet agents, cholesterol-lowering agents etc. ${ }^{3,4}$ However, it is key to appreciate that the pathogenesis of vein graft failure differs during the first year post-CABG, where it is mainly neointimal hyperplasia, as opposed to the subsequent years, where it is predominantly atherosclerosis. ${ }^{3,4}$

Surgical harvesting of the saphenous vein results in a loss of continuity of the vasa vasorum that provides nutrition, oxygen, and removes waste products. This results in hypoxemia of the harvested vein and formation of free radicals, predisposing to early vein graft disease. ${ }^{5}$ Furthermore, post-systemic implantation, the vein graft is immediately subjected to the pulsatile arterial system, leading to longitudinal wall (shear) stress. ${ }^{6}$ This causes neointimal hyperplasia However, this newly formed endothelium is functionally compromised and prone to thrombosis and stenosis.

\footnotetext{
From the Department of Advanced Cardiopulmonary Therapies and Transplantation, The University of Texas Health Science Center at Houston, Mc Govern Medical School, Houston, Tex.

Disclosures: Author has nothing to disclose with regard to commercial support.

Received for publication March 19, 2020; revisions received March 19, 2020; accepted for publication March 20, 2020; available ahead of print April 6, 2020.

Address for reprints: Shuab Omer, MD, Department of Advanced Cardiopulmonary Therapies and Transplantation, The University of Texas Health Science Center at Houston, McGovern Medical School, Houston, TX 77030 (E-mail: shuab.omer@ uth.tmc.edu).

J Thorac Cardiovasc Surg 2022;163:1040-1

$0022-5223 / \$ 36.00$

Copyright $(2) 2020$ by The American Association for Thoracic Surgery

https://doi.org/10.1016/j.jtcvs.2020.03.080
}

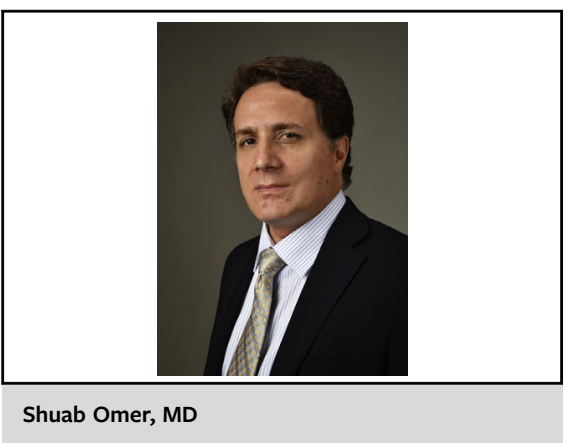

CENTRAL MESSAGE

Lack of benefit of lipid-lowering agents on SVG patency in the first year S/P CABG is a reflection of basic mechanism of early graft failure, which is thrombosis rather than atherogenesis.

Beyond the first year of graft implantation, atherosclerosis rather than neointimal hyperplasia becomes the main culprit of vein graft attrition. Essentially, the predisposing factors as well as the process of atheroma formation are the same for vein grafts and native arteries and, like native atheromas, graft atheromas can rupture and cause thrombotic occlusion of the graft. ${ }^{8,9}$

Based on these differing underlying pathogenic mechanisms for vein graft attrition, several strategies have been proposed to improve vein graft patency post-CABG from antiplatelet agents to lipid-lowering agents. ${ }^{10,11}$ In this issue of the Journal, Zhu and colleagues ${ }^{12}$ have presented the post hoc analysis of the DACAB (Different Antiplatelet Therapy Strategy After Coronary Artery Bypass Graft Surgery) trial, ${ }^{13}$ in which they demonstrated the impact of baseline low-density lipoprotein cholesterol (LDL-C) levels on vein graft patency in patients on ticagrelor with or without aspirin 1 year after CABG and concluded that baseline LDL-C is not associated with 1 -year vein graft patency after CABG and that regardless of the baseline LDL-C levels, ticagrelor + aspirin was superior to aspirin alone in maintaining vein graft patency. They further hypothesized that the primary factor causing early vein graft failure might not be atherosclerosis but thrombosis.

This study lends further credence to the fact that based on both experimental and clinical experience, early vein graft failure within a year is mainly due to thrombotic and technical events rather than atherogenesis, which takes longer to 
manifest. Thus, it comes as no surprise that the study by Zhu and colleagues ${ }^{12}$ was not able to demonstrate any beneficial effect of aggressive lowering of LDL-C in the first year. It is plausible that the much-awaited long-term follow-up of the same study might show different results.

However, it is also important to appreciate that the study by Zhu and colleagues ${ }^{12}$ is a post hoc analysis of the DACAB trial and was not designed to study the effect of LDL-C on vein patency. A very large percentage of patients (approximately $75 \%$ ) underwent off-pump coronary artery bypass; thus, the results of this study cannot be generalized to the majority of on pump cases.

It is also very difficult to ascertain from this study or most other studies of this type whether the benefits of antiplatelet or lipid-lowering agent are due to prevention of native vessel disease, graft disease, or combination of the two. Also, the DACAB trial excluded patients older than 80 years. The exclusion of these older patients from clinical trials creates challenges in generalizing the results to the entire geriatric population.

In summary, dual-antiplatelet agents such as ticagrelor and aspirin show benefit over just aspirin alone in patients post CABG; however, the apparent lack of benefit of additional aggressive lipid lowering on vein graft patency in the first year is most likely a reflection of the differing basic pathogenic mechanism of early graft failure, mainly due to thrombosis as opposed to atherogenesis. Appropriately designed studies with long-term follow-up are needed to elucidate the impact of aggressive lipid-lowering agents on graft patency and major adverse cardiac events after CABG.

\section{References}

1. FitzGibbon GM, Leach AJ, Keon WJ, Burton JR, Kafka HP. Coronary bypass graft fate: angiographic study of 1,179 vein grafts early, one year, and five years after operation. J Thorac Cardiovasc Surg. 1986;91:773-8.

2. FitzGibbon GM, Kafka HP, Leach AJ, Keon WJ, Hooper GD, Burton JR. Coronary bypass graft fate and patient outcome: angiographic follow-up of 5,056 grafts related to survival and reoperation in 1,388 patients during 25 years. $J$ Am Coll Cardiol. 1996;28:616-26.

3. Harskamp RE, Lopes RD, Baisden CE, de Winter RJ, Alexander JH. Saphenous vein graft failure after coronary artery bypass surgery: pathophysiology, management, and future directions. Ann Surg. 2013;257:824-33.

4. Alkhalil M. Effects of intensive lipid-lowering therapy on mortality after coronary bypass surgery: a meta-analysis of 7 randomised trials. Atherosclerosis. 2020;293:75-8.

5. Dobrin PB, Littooy FN, Endean ED. Mechanical factors predisposing to intimal hyperplasia and medial thickening in autogenous vein grafts. Surgery. 1989;105: 393-400.

6. Brody WR, Kosek JC, Angell WW. Changes in vein grafts following aortocoronary bypass induced by pressure and ischemia. J Thorac Cardiovasc Surg. 1972; 64:847-54.

7. Powell JT, Gosling M. Molecular and cellular changes in vein grafts: influence of pulsatile stretch. Curr Opin Cardiol. 1998;13:453-8.

8. Cho KR, Kims JS, Choi JS, Kim KB. Serial angiographic follow-up of grafts one year and five years after coronary artery bypass surgery. Eur J Cardiothorac Surg. 2006;29:511-6.

9. Cox JL, Chiasson DA, Gotlieb AI. Stranger in a strange land: the pathogenesis of saphenous vein graft stenosis with emphasis on structural and functional differences between veins and arteries. Prog Cardiovasc Dis. 1991;34:45-68.

10. Alkhalil M. Effects of intensive lipid-lowering therapy on mortality after coronary bypass surgery: a meta-analysis of 7 randomised trials. Atherosclerosis. 2020;293:75-8.

11. Gupta S, Belley-Cote EP, Agahi P, Basha A, Jaffer I, Mehta S, et al. Antiplatele therapy and coronary artery bypass grafting: analysis of current evidence with a focus on acute coronary syndrome. Can J Cardiol. 2019;35:1030-8.

12. Zhu J, Zhu Y, Zhang M, Xue Q, Hu J, Liu H, et al. Influence of lipoproteins and antiplatelet agents on vein graft patency 1 year after coronary artery bypass grafting. J Thorac Cardiovasc Surg. 2022;163:1030-9.e4.

13. Zhao Q, Zhu Y, Xu Z, Cheng Z, Mei J, Chen X, et al. Effect of ticagrelor plus aspirin, ticagrelor alone, or aspirin alone on saphenous vein graft patency 1 year after coronary artery bypass grafting: a randomized clinical trial. JAMA 2018;319:1677-86. 